\title{
A Review on VOCs Control Technology Using Electron Beam
}

\author{
Youn-Suk Son ${ }^{1)}$, Ki-Joon Kim ${ }^{2)}$ and Jo-Chun Kim ${ }^{1,3), *}$ \\ ${ }^{1)}$ Department of Advanced Technology Fusion, Konkuk University, 1 Hwayang-dong, Gwangjin-gu, Seoul 143-701, Korea \\ ${ }^{2)}$ Emission Source Research Division, National Institute of Environmental Research, Incheon 404-708, Korea \\ ${ }^{3)}$ Department of Environmental Engineering, Konkuk University, 1 Hwayang-dong, Gwangjin-gu, Seoul 143-701, Korea \\ *Corresponding author. Tel: +82-2-455-2994, E-mail: jckim@konkuk.ac.kr
}

\begin{abstract}
The removal characteristics for aromatic and aliphatic VOCs by electron beam (EB) were discussed in terms of several removal variables such as initial VOC concentration, absorbed dose, background gas, moisture content, reactor material and inlet temperature. It was reviewed that only reactor material was an independent variable among the potential control factors concerned. It was also suggested that main mechanism by EB should be radical reaction for the VOC removal rather than that by primary electrons. It was discussed that the removal efficiency of benzene was lower than that of hexane due to a closed benzene ring. In the case of aromatic VOCs, it was observed that the decomposition of the VOCs with more functional groups attached on the benzene ring was much easier than those with less ones. As for aliphatic VOCs, it was also implied that the longer carbon chain was, the higher the removal efficiency became. An EB-catalyst hybrid system was discussed as an alternative way to remove VOCs more effectively than EB-only system due to much less by-products. This hybrid included supporting materials such as cordierite, Y-zeolite, and $\gamma$-alumina.
\end{abstract}

Key words: Electron beam, Aromatic VOC, Catalytic oxidation, By-product, Toluene

\section{INTRODUCTION}

Volatile organic compounds (VOCs) are emitted into the atmosphere from a variety of industrial processes. They have adverse effects on the environment and public health through the formation of ozone, carcinogenic and toxic substance. Therefore, many countries have paid more attention to efficient control methods for these VOCs (Jeon et al., 2008; Kim et al., 2004; Kim, 2002).
There are many different traditional techniques to control VOCs emissions such as carbon adsorption, absorption, catalytic oxidation, thermal incineration, and biotreatment. There techniques share both advantages and limitations (Kim et al., 2005; Kim et al., 2004; Faisal and Aloke, 2000). Table 1 shows a brief review for VOCs removal methods (Khan and Ghoshal, 2000; Rafson, 1998). Recently, there have been many researches on the decomposition of VOCs using electron beam (EB), plasma, and photocatalytic oxidation/ $\mathrm{UV}$ and hybrid system treatment in order to resolve their problems (Boulamanti et al., 2008; Chmielewski et al., 2007; Chmielewski, 2007; Chaichanawong et al., 2005; Kim et al., 2005; Chmielewski and HajiSaeid, 2004; Tanthapanichakoon et al., 2004; Han et al., 2003; Licki et al., 2003). However, most plasma and corona methods needed energy over $100 \mathrm{~J} / \mathrm{L}$ for efficient VOC treatment (Lu et al., 2006; Kim et al., 2005). On the other hand, in terms of its energy effectiveness, it was reported that efficiency of VOC removal by EB was 50 times higher than that by plasma or corona (Penetrante et al., 1997; Penetrante et al., 1995). Furthermore, it is well known that the economic range of absorbed dose in EB technology is below $10 \mathrm{kGy}$ $(\sim 10 \mathrm{~J} / \mathrm{L})$.

The method of VOC removal by EB irradiation has been considered one of the most upgraded and novel technologies (Kim et al., 2004; Licki et al., 2003; Hirota et al., 2002; Kim, 2002; Ogata et al., 1999; Hirota et al., 1995a; Paur et al., 1991). EB method can be applied to high emission rate and/or low concentration of source facilities at ambient air temperature and requires relatively low dose. However, one of disadvantages associated with this technique is the formation of by-products (Kim et al., 2010; Sun et al., 2009; Jeon et al., 2008; Kim et al., 2005). In order to solve that problem, a few research groups have investigated the decomposition of VOCs using a hybrid technology such as combination of EB or plasma with catalyst (Kim et al., 2010, 2005, 2004; Jeon et al., 2008; Ogata et al., 
Table 1. Comparison of various VOC control techniques.

\begin{tabular}{|c|c|c|c|}
\hline Techniques & $\begin{array}{l}\text { Annual operating } \\
\text { cost }(\$ / \mathrm{cfm})\end{array}$ & $\begin{array}{c}\text { Removal } \\
\text { efficiency }(\%)\end{array}$ & Positive and negative remarks \\
\hline Absorption & $25-120$ & $90-98$ & $\begin{array}{l}\text {-Product recovery can offset annual operating costs } \\
\text {-Requires rigorous maintenance } \\
\text { - Requires pretreatment of the VOCs }\end{array}$ \\
\hline $\begin{array}{c}\text { Adsorption } \\
\text { (Activated carbon) }\end{array}$ & $10-35$ & $80-90$ & $\begin{array}{l}\text { - Recovery of compounds, which may offset annual } \\
\text { operating costs } \\
\text {-Susceptible to moisture, and some compounds } \\
\text { (ketones, aldehydes, and esters) can clog the pores }\end{array}$ \\
\hline Biofiltration & $15-75$ & $60-95$ & $\begin{array}{l}\text { - Requires less initial investment, less non-harmful secondary } \\
\text { waste, and non-hazardous } \\
\text {-Slow, and selective microbes decomposes selective organics, } \\
\text { thus requires a mixed culture of microbes }\end{array}$ \\
\hline Condensation & $20-120$ & $70-85$ & $\begin{array}{l}\text {-Product recovery can offset annual operating costs } \\
\text { - Requires rigorous maintenance }\end{array}$ \\
\hline Catalytic oxidation & $15-90$ & $90-98$ & $\begin{array}{l}\text {-Energy recovery is possible (maximum up to } 70 \% \text { ) } \\
\text { - Efficiency is sensitive to operating conditions }\end{array}$ \\
\hline Thermal oxidation & $\begin{array}{c}15-90 \\
\text { (Recuperative) } \\
20-150 \\
\text { (Regenerative) }\end{array}$ & $95-99$ & $\begin{array}{l}\text { - Energy recovery is possible (maximum up to } 85 \% \text { ) } \\
\text { - Halogenated and other compounds may require additional } \\
\text { control equipment }\end{array}$ \\
\hline Zeolite & $15-40$ & $90-96$ & $\begin{array}{l}\text { - Effective in more than } 90 \% \text { RH, Recovery of compounds } \\
\text { offsets annual operating costs } \\
\text {-High cost of zeolite, restricted availability }\end{array}$ \\
\hline $\begin{array}{l}\text { Membrane } \\
\text { separation }\end{array}$ & $15-30$ & $90-99$ & $\begin{array}{l}\text { - No further treatment, recovery of solvent may } \\
\text { offset the operating costs } \\
\text {-Membranes are rare and costly }\end{array}$ \\
\hline
\end{tabular}

(Source : Khan and Ghoshal, 2000)

1999; Kohno et al., 1998). Therefore, the objective of this research is to review all the subjects covering EB for the decomposition of aromatic and aliphatic VOCs.

\section{REVIEW ON VOC REMOVAL TECHNIQUE USING EB}

\subsection{What is the Principle of Electron Beam Process to Decompose VOCs?}

The EB operation time is quite short because the electrons are generated during $10^{-18}-10^{-12}$ seconds and interact with the gas molecules. Besides, this reaction produces free radicals and ions during $10^{-8}$ $10^{-1}$ seconds (Kim et al., 2006b; Kim et al., 2005; Kim, 2002). When air is irradiated by an electron beam with the energy of electrons of $1 \mathrm{MeV}$, the maximum penertration range is about $2.8-3 \mathrm{~m}$ (Vazquez et al., 2002).

More specifically, when the energy of the fast electrons is absorbed in the air, it causes ionization and excitation processes of the nitrogen and oxygen molecules in the air stream. At first, Primary species and secondary electrons are formed, and the latter are thermalized within $1 \mathrm{~ns}$ in air at 1 bar pressure. These primary species and the thermalized secondary electrons react with VOCs by a series of reactions to cause their decomposition (Chmielewski et al., 2007). After irradiation, primary electrons interact with gas creating various ions and free radicals, the primary species formed include $\mathrm{e}^{-}, \mathrm{N}_{2}{ }^{+}, \mathrm{N}^{+}, \mathrm{O}_{2}^{+}, \mathrm{O}^{+}, \mathrm{H}_{2} \mathrm{O}^{+}, \mathrm{OH}^{+}$, $\mathrm{H}^{+}, \mathrm{CO}_{2}{ }^{+}, \mathrm{CO}^{+}, \mathrm{N}_{2}{ }^{*}, \mathrm{O}_{2}{ }^{*}, \mathrm{~N}, \mathrm{O}, \mathrm{H}, \mathrm{OH}$, and $\mathrm{CO}$. In addition, in the case of high water vapor concentration, the oxidizing radicals $\mathrm{OH}$ and $\mathrm{HO}_{2}{ }^{\circ}$, and exited ions as $\mathrm{O}\left({ }^{3} \mathrm{P}\right)$ are the most important product (Chmielewski, 2007; Licki et al., 2003). These species take part in a variety of ion-molecule reactions, neutralization reactions, and dimerization (Person and Ham, 1988).

\subsection{Absorbed Dose and Initial Concentration}

The decomposition characteristics of representative VOCs such as toluene, benzene, and styrene were investigated as a function of initial concentration and absorbed dose (Kim et al., 2005; Kim, 2002). They found that the removal efficiencies of these target compounds increased as their concentrations decreased or the absorbed doses increased. Sun et al. (2009) also suggested that the decomposition efficiency of toluene 
Table 2. A comparison of removal efficiencies for aromatic and aliphatic VOCs among different studies.

\begin{tabular}{|c|c|c|c|c|}
\hline $\begin{array}{c}\text { VOC } \\
\text { compounds }\end{array}$ & $\begin{array}{c}\text { Absorbed } \\
\text { dose (kGy) }\end{array}$ & $\begin{array}{l}\text { Concentration } \\
(\mathrm{ppmC})\end{array}$ & $\begin{array}{c}\text { Removal } \\
\text { efficiency }(\%)\end{array}$ & Reference \\
\hline o-xylene & 10 & $\begin{array}{l}744 \\
784 \\
176 \\
184\end{array}$ & $\begin{array}{l}65 \\
54 \\
87 \\
85\end{array}$ & $\begin{array}{l}\text { Hakoda et al., } 1998 \\
\text { Hashimoto } \text { et al., } 2000 \\
\text { Hirota } \text { et al., } 2002 \\
\text { Hirota } \text { et al., } 1995 \mathrm{~b}\end{array}$ \\
\hline \multirow{4}{*}{ Toluene } & 10 & $\begin{array}{l}1050 \\
945 \\
900 \\
630\end{array}$ & $\begin{array}{l}43 \\
60 \\
50 \\
66\end{array}$ & $\begin{array}{l}\text { Hakoda } \text { et al., } 1998 \\
\text { Hashimoto } \text { et al., } 2000 \\
\text { Han } \text { et al., } 2003 \\
\text { Kim } \text { et al., } 2004\end{array}$ \\
\hline & 8.9 & 1500 & 60 & Kim et al., 2005 \\
\hline & 6 & 60 & 90 & Kim, 2002 \\
\hline & 14.5 & $\begin{array}{c}224 \\
443.8 \\
546\end{array}$ & $\begin{array}{c}50 \\
37 \\
34.5\end{array}$ & Sun et al., 2009 \\
\hline Butylacetate & 10 & 240 & 60 & $\begin{array}{l}\text { Mätzing et al., } 1994 \\
\text { Hirota et al., 1995b } \\
\text { Hirota } \text { et al., 1995a }\end{array}$ \\
\hline Ethylbenzene & 10 & 960 & 60 & $\begin{array}{l}\text { Han et al., } 2003 \\
\text { Hirota } \text { et al., } 1995 \mathrm{a}\end{array}$ \\
\hline \multirow{2}{*}{ Styrene } & 6 & 640 & 95 & Kim et al., 2004 \\
\hline & 8.9 & 1500 & 80 & Kim et al., 2005 \\
\hline Hexane & 10 & $\begin{array}{l}600 \\
300 \\
140 \\
\end{array}$ & $\begin{array}{l}50 \\
88 \\
96 \\
\end{array}$ & Kim et al., 2006b \\
\hline \multirow{2}{*}{ Methane } & 5 & $\begin{array}{c}10600 \\
800 \\
270 \\
100\end{array}$ & $\begin{array}{c}3.8 \\
18.3 \\
20.7 \\
548\end{array}$ & \multirow{2}{*}{ Kim et al., 2006a } \\
\hline & 20 & $\begin{array}{c}10600 \\
800 \\
270 \\
100\end{array}$ & $\begin{array}{c}6.4 \\
20.8 \\
26.3 \\
58.7\end{array}$ & \\
\hline
\end{tabular}

increased with absorbed dose but decreased with initial concentrations. The decomposition of aromatic VOCs (toluene, ethylbenzene, xylene and chlorobenzene) has been carried out using the similar systems as above. Han et al. (2003) observed that decomposition efficiencies were $55-65 \%$ for "non-chlorinated" aromatic VOCs (initial concentration from 50 to $2,000 \mathrm{ppm}$ ) and $85 \%$ for chlorobenzene (initial concentration from 150 to $300 \mathrm{ppm}$ ). This trend was also observed similarly for aliphatic VOCs such as methane and hexane (Kim et al., 2006a, b). Besides, Hirota et al. (1995a) revealed that the removal efficiency of xylene was higher than that for butylacetate in the dose range 0$10 \mathrm{kGy}$. A compilation of the VOCs removal efficiencies obtained from various electron beam studies is presented in Table 2. It was found that different research groups used different initial VOC concentrations and dose ranges.

\section{3 Effect of Different Background Gases on Aromatic and Aliphatic VOCs Decomposition}

Toluene (140 ppmC) removal at different matrix gases in a batch system was studied by Kim (2002). The decomposition efficiency under He atmosphere was significantly lower than other gaseous conditions. Kim et al. (2006b) conducted hexane removal at the same matrix of gaseous conditions and found that the removal trend was very similar to the previous study of Kim (2002). However, decomposition efficiencies of toluene in different background gases were slightly higher than those of hexane. Likewise, Chmielewski et al. (2007) evaluated 1,4-dichlrobenzene (DCB) decomposition in different base gas mixtures at the initial concentration 
$50 \mathrm{ppm}$. It was found that the decomposition efficiency of 1,4-DCB in nitrogen was higher than that in air. It indicates that electrons generated by electron beam radiolysis did not lead to considerable decomposition of those compounds. Sun et al. (2006) also reported that the order of background gases to affect the decomposition of 1,4-DCB was as follows: $\mathrm{N}_{2}>$ Air $>1.027$ $\% \mathrm{NO} / \mathrm{N}_{2}$. On the other hand, Kim (2002) suggested that order of the background gases $\left(\mathrm{N}_{2}>\right.$ air $\left.>\mathrm{O}_{2}>\mathrm{He}\right)$ should be different from those $\left(\mathrm{O}_{2}>\right.$ air $\left.>\mathrm{H}_{2}>\mathrm{He}\right)$ for TCE decomposition (Won et al., 2002). It was also found that the decomposition efficiency of TCE under helium atmosphere was significantly low because of the stability of background gases.

\subsection{Effect of Moisture on Aromatic and Aliphatic VOCs Degradation}

The effect of water vapor on the decomposition of aromatic VOCs in batch and flow system using EB was studied by Kim (2002). In this work, the addition of water vapor into the reactors of batch and flow systems resulted in $5-10 \%$ and $15-20 \%$ increase of target VOC decomposition efficiencies, respectively, compared to the work without water vapor injection. It was presented that $\mathrm{OH}$ radical played a pivotal role in the VOC removal reaction (Sun et al., 2009, 2008; Chmielewski et al., 2007; Penetrante et al., 1998). Won et al. (2002) also found that the decomposition efficiency for different initial trichloroethylene concentrations with the addition of water vapor was slightly larger than that in dry air at $10-20 \mathrm{kGy}$. Besides, it was observed that water vapor addition enhanced the removal efficiency of chlorinated organic compounds (Chmielewski et al., 2007). For chlorinated aliphatic hydrocarbons' decomposition, Sun et al. (2006) also found that $\mathrm{OH}$ radical reaction with VOCs play major role for VOCs removal.

\subsection{Comparison of Aromatic and Aliphatic VOCs Degradation}

As for aliphatic VOC, the removal efficiency of ndecane $\left(\mathrm{C}_{10} \mathrm{H}_{22}\right)$ by EB was the highest. Then, those of n-hexane $\left(\mathrm{C}_{6} \mathrm{H}_{14}\right)$, n-butane $\left(\mathrm{C}_{4} \mathrm{H}_{10}\right)$, and methane $\left(\mathrm{CH}_{4}\right)$ were followed (personal communication). On the other hand, when the decomposition efficiency for aromatic VOCs was considered, that for benzene $\left(\mathrm{C}_{6} \mathrm{H}_{6}\right)$ was the lowest. In contrast, those of toluene $\left(\mathrm{C}_{7} \mathrm{H}_{8}\right)$, ethylbenzene $\left(\mathrm{C}_{8} \mathrm{H}_{10}\right)$, and p-xylene $\left(\mathrm{C}_{8} \mathrm{H}_{10}\right)$ were similar. When $\mathrm{n}$-hexane was compared with benzene, it was revealed that the latter was more difficult to decompose than the former. Besides, Chmielewski et al. (2007) found that the removal efficiency for chlirinated compounds with higher numbers of chlorine groups was higher than their lower numbered countparts.

\section{6 The Characteristics of Decomposition by Different Reactor Materials}

In order to observe removal efficiencies by different container materials, a flow system was used in this study. All experimental approaches are well depicted elsewhere (Kim, 2002). Transition metals (Fe, Cu, Zn and $\mathrm{Al}$ ) and stainless steel were employed as reactor materials to compare toluene $(160 \mathrm{ppmC})$ removal characteristics at the same conditions. As for different reactor materials regarding $\mathrm{SS}, \mathrm{Fe}, \mathrm{Cu}, \mathrm{Zn}, \mathrm{Al}$, the degradation efficiency was 57.9-61.8, 59.9-61.65, 62.3-62.9, 59.2-62.4 and 58.4-60.0\%, respectively. This work clearly showed similar removal efficiencies regardless of reactor materials. This result suggested that decomposition efficiency not be affected by reactor materials.

\subsection{The Characteristics of VOC Decomposition by Inlet Gas Temperature}

The characteristics of VOC removal efficiency by inlet temperature were investigated by Kim (2002). The decomposition efficiency of toluene was approximately constant from $30^{\circ} \mathrm{C}$ to $130^{\circ} \mathrm{C}$. However, it was decreased substantially when the temperature rose up to $170^{\circ} \mathrm{C}$. It was found that the energy-rich $\mathrm{OH}$ aromatic adduct was removed back to toluene at the high temperature of $170^{\circ} \mathrm{C}$. A more detailed explanation of reaction and back reaction mechanism can be found in a previous paper (Kim, 2002).

\section{8 By-products Generated from VOCs by EB Process}

In general, it is known that ozone, $\mathrm{CO}, \mathrm{CO}_{2}$, aerosol and other trace compounds such as benzene, benzaldehyde, etc. are by-products found in the course of radiolysis destruction of various VOCs (Kim et al., 2010, 2006a, 2005, 2004; Sun et al., 2009; Han et al., 2003; Kim, 2002; Won et al., 2002; Hirota et al., 1995a, b; Päur and Mätzing, 1993; Päur et al., 1991).

\section{8. 1 Formation of Ozone, $\mathrm{CO}$, and $\mathrm{CO}_{2}$}

In general, ozone concentration generated from irradiation systems for VOC treatment increased as absorbed dose increased (Kim et al., 2004; Hiroto et al., 1995). $\mathrm{CO}$ and $\mathrm{CO}_{2}$ concentration also increased with dose rise (Won et al., 2002), and these two compounds occupied $56 \%$ among the total by-products at $18 \mathrm{kGy}$. Kim et al. (2004) also found that ozone and $\mathrm{CO}_{2}$ levels by irradiation of toluene were $164 \mathrm{ppm}$ and $14.4 \%$ at 10 $\mathrm{kGy}$, respectively, and were proportional to temperature. Besides, the $\mathrm{CO}_{2}$ yield for the by-product analysis by $\mathrm{EB}$ was about $17 \%$ (Kim et al., 2005). On the 
other hand, the $\mathrm{CO}$ and $\mathrm{CO}_{2}$ yields were almost negligible up to $18 \mathrm{kGy}$ while toluene was destructed (Han et al., 2003). Although the yield was different with respect to various compounds, the amount of $\mathrm{CO}$ and $\mathrm{CO}_{2}$ produced was from 10 to $56 \%$ among decomposed VOCs (Won et al., 2002; Hirota et al., 1995a, b; Mätzing et al., 1994; Päur and Mätzing, 1993; Päur et al., 1991). However, the amount of ozone produced by electron beam can be mitigated using catalysts according to researches by Kim et al. (2004) and Jeon et al. (2008).

\section{8. 2 Other Trace Compounds}

By-products generated from VOCs decomposition process were studied by Kim et al. (2010, 2005). In these results, benzene, benzaldehyde, and other trace materials were found as by-products out of toluene removal using EB. Benzaldehyde was also reported as a by-product in previous works (Sun et al., 2009; Han et al., 2003). This benzaldehyde formation strongly suggested the involvement of the Russell's and Bennett's mechanisms associated with the peroxyl radicals (Kim et al., 2010). Other oxidation reactions might also occur as reported by Shepson et al. (1984) and Atkinson (1985). Besides, Han et al. (2003) reported that the main by-products in the radiolytic oxidizing of toluene were dipropyl 1,2-benzenedicarboxylic acid and other trace compounds such as acetone, hexane, benzene.

In the study on butylacetate removal conducted by Mätzing et al. (1994), main by-products after EB irradiation were acetate, and minor ones were formiate, propion, and butyrate. The artifacts by o-xylene and butylacetate decomposition were confirmed by Hirota et al. (1995a, b). It was reported that formic acid, acetic acid, propionic acid and butyric acid were identified as by-products in their work at $2-10 \mathrm{kGy}$.

Han et al. (2003) identified methly chloride, dipropyl 1,2-benzenedicarboxylic acid, toluene, nitromethane as by-products generated from the EB irradiation of ethlybenzene and chlorobenzene. Also, those generated from trichloroethylene by EB irradiation were investigated by Won et al. (2002). It was found that the main by-products were $\mathrm{HCl}$, dichloroacetic acid (DCAA), dicloroacetyl chloride (DCAC) and dichloroethly ester acetic acid (DCEA). Among these compounds, DCAA, DCAC, DCEA were recognized as intermediate products, which were decomposed to produce $\mathrm{CO}$ and $\mathrm{CO}_{2}$.

By-products from hexane decomposition using EB were identified by Kim et al. (2006a). In this case, they were acetone, benzene, 2-hexanone, 3-hexanone, etc. Especially, acetone and benzene generated from this process continuously increased as adsorbed dose increased. On the other hand, the production of 2-hexa- none and 3-hexanone significantly increased when the adsorbed dose increased up to $2.5 \mathrm{kGy}$. However, the production rate of those compounds relatively decreased as absorbed dose increased from 2.5 to $10 \mathrm{kGy}$.

\section{ADVANTAGE OF EB-CATALYST COUPLING SYSTEM}

One of disadvantages associated with EB technique is the formation of by-products (Kim et al., 2010; Sun et al., 2009; Jeon et al., 2008; Kim et al., 2005). In order to solve the problem, some research groups have carried out works on decomposition of VOCs using hybrid technology such as combined EB or plasma with catalyst (Kim et al., 2010, 2005, 2004; Jeon et al., 2008; Moon, 2003; Ogata et al., 1999; Kohno et al., 1998). In this study, the EB-catalyst coupling system has been introduced as an advanced oxidizing technology as follows.

\subsection{Comparison of Removal Efficiency by Hybrid Reactor Type}

Recently, a research group has demonstrated the effectiveness of the EB-catalyst hybrid system for the decomposition of VOCs (Kim et al., 2010, 2008, 2005, 2004). In order to compare the combined types of hybrid system such as only electron beam (EB-only), EB-ceramic, EB-catalyst and EB-catalyst-support material, a hybrid study was carried out by Kim et al. (2004). It was found that removal efficiencies for toluene (initial concentration: $82 \mathrm{ppmC}$, flow gas rate: $670 \mathrm{~m}^{3} / \mathrm{h}$ ) were $26.5-66,39.1-76.1,40.6-89.3$ and $63.9-$ $95.5 \%$, respectively, while the adsorbed dose was increased from 2 to $10 \mathrm{kGy}$. The trend of styrene decomposition was similar to that for toluene at the same conditions.

Moon (2003) found that the removal efficiency of toluene using plasma combined with $\mathrm{Pt} / \mathrm{Al}_{2} \mathrm{O}_{3}$ was $15 \%$ higher than that using only plasma at the same conditions. Besides, it was reported that DBD (dielectric barrier discharge)-Mn catalyst hybrid system enhanced toluene removal more efficiently than sole DBD (Magureanu et al., 2005). In the study on SDR (silent discharge reactors) with and without coupling $\mathrm{MnO}_{2}$ for benzene removal, the decomposition efficiency for SDR- $\mathrm{MnO}_{2}$ coupling was higher than that of only SDR (Futamura and Gurusamy, 2005; Furamura et al., 2004).

Kim et al. (2005) conducted an experiment for toluene removal to compare the removal efficiency for the EB-ceramic with that for EB-catalyst hybrid. It was concluded that decomposition efficiency of EBcatalyst hybrid system was higher than that of EB- 
ceramic hybrid. Also, in the comparison study on the independent effect of EB-catalyst and catalyst itself, the decomposition efficiency with EB-catalyst revealed a $10 \%$ improvement in toluene treatment and an increase of $20 \%$ in styrene treatment. The by-products identified in their studies were aerosol, $\mathrm{CO}, \mathrm{CO}_{2}$ and traces of benzene, benzaldehyde, and other compounds. Kim's group who applied the hybrid technique showed that there was a considerable increase in $\mathrm{CO}_{2}$, while the amount of aerosol decreased to half compared to EB-only (Jeon et al., 2008; Kim et al., 2005, 2004).

\subsection{The Decomposition Characteristics by Various Catalysts}

In order to evaluate the toluene removal efficiencies by various catalysts in EB-catalyst hybrid system, noble $(\mathrm{Pt}, \mathrm{Pd})$ and transition metal $(\mathrm{Mn}, \mathrm{Cu})$ were deposited to ceramic honeycomb, when initial concentration of toluene was $1,500 \mathrm{ppmC}$ (Jeon et al., 2008). First, the decomposition efficiency of EB, EB-ceramic, and EB-ceramic (Pt 1 wt.\%) were compared in order to estimate the effect of ceramic itself. It was confirmed that there was no momentous effect of ceramic on the removal efficiencies of the aromatic VOCs.

In the presence of $\mathrm{Pt}, \mathrm{Pd}, \mathrm{Mn}$ and $\mathrm{Cu}$ catalysts with EB system, the decomposition efficiencies were increased approximately by $33,37,22$ and $6 \%$ when compared to the EB-only. Especially, the $\mathrm{CO}_{2}$ selectivity of EB-Pt hybrid was considerably higher than the hybrid with catalysts such as $\mathrm{Pd}, \mathrm{Mn}$, and $\mathrm{Cu}$ at a relatively low irradiation dose. More detailed illustration was reported in a previous literature (Jeon et al., 2008)

\section{3 The Removal Efficiencies of Toluene with EB-catalyst Hybrid by Loading Rate of Catalysts}

Jeon et al. (2008) have conducted a study about comparison of decomposition efficiencies of toluene by catalyst $(\mathrm{Pt}, \mathrm{Pd}$, and $\mathrm{Mn})$ loading rates in a hybrid system. The removal efficiencies did not differ eminently with respect to different loading rates.

\subsection{The Comparison of Removal Efficiency by Support Materials}

The decomposition efficiency of toluene by combined support material such as cordierite, Y-zeolite, and $\gamma$-alumina with EB processes was investigated by Kim et al. (2010). This result indicated that the removal efficiency of platinum catalyst was higher than that of palladium. It was also found that Y-zeolite showed the highest efficiency among support materials concerned. Besides, it was found that roughly $100 \%$ decomposition of toluene was observed at $8.9 \mathrm{kGy}$ when catalyst with $12 \mathrm{wt} \%$ of $\mathrm{Pt}$ and Pd was used.

\section{INDUSTRIAL APPLICATIONS OF ELECTRON BEAM}

Research on the EB process for decomposition of gases pollutants has been continued in many countries such as Japan, U.S.A, Germany and Poland, after Ebara Co. demonstrated the removal of $\mathrm{SO}_{2}$ using linear accelerator in 1970 (Frnak, 1995; Machi, 1983). Two pilot plants for the removal of $\mathrm{SO}_{2}$ and $\mathrm{NO}_{\mathrm{x}}$ were installed by Japanese Ebara company in Karlsruhe, Germany and Indianapolis, USA. The former $(0.3 \mathrm{Mev}$ and $180 \mathrm{~kW}$ ) had a capacity of $16,000-32,000 \mathrm{~m}^{3} / \mathrm{h}$ and the latter $(0.8 \mathrm{Mev}$ and $160 \mathrm{~kW}) 10,000-20,000$ $\mathrm{m}^{3} / \mathrm{h}$. The Ebara company built, first, a full-scale plant in China, its capacity was $320 \mathrm{~kW}$ for the treatment of $270,000 \mathrm{~N} \mathrm{~m}^{3} / \mathrm{h}$ of flue gas. Its removal efficiency was $80 \%$ for $\mathrm{SO}_{\mathrm{x}}$ and $20 \%$ for $\mathrm{NO}_{\mathrm{x}}$ (Chmielewski, 2007; Doi et al., 2000). The more detailed contents on the pilot and industrial plants can be found in previous papers (Chmielewski, 2007; Chmielewski and Haji-Saeid, 2004).

The studies of EB process for VOCs decomposition in flue gas began in advanced countries in the early 1990s. In the case of Poland, a research on simultaneous removal of $\mathrm{SO}_{\mathrm{x}}, \mathrm{NO}_{\mathrm{x}}$, and VOCs was conducted in Kaweczun electric power stations. Fundamental studies were carried out by many scientists after that (Machi, 2004; Licki et al., 2003; Chmielewski et al., 2002; Hashimoto et al., 2000; Ostapczuk et al., 1999; Hakoda et al., 1998; Wu et al., 1997; Hirota et al., 1995a; Mätzing et al., 1994; Päur and Mätzing, 1993). Furthermore, recent papers documented that EB process was technically and economically practicable (Chmielewski and Haji-Saeid, 2004; Hirota et al., 2003). On the other hand, no VOC control plant has been installed since the VOC technique is still under development.

\section{SUMMARY}

In this work, VOC removal techniques by electron beam (EB) irradiation were reviewed. VOC removal variables such as initial VOC concentration, absorbed dose, background gas, moisture content, reactor material and inlet temperature were compared and discussed for aliphatic and aromatic VOCs. However, it was found that only reactor material was an independent variable among them. It was also concluded that radical reaction was a major mechanism for VOC decomposition rather than that by primary electrons.

Benzene $\left(\mathrm{C}_{6} \mathrm{H}_{6}\right)$ and hexane $\left(\mathrm{C}_{6} \mathrm{H}_{14}\right)$ were compared in terms of their removal efficiencies, and it was found 
the decomposition efficiency of hexane was higher than that of benzene. In the case of aromatic VOCs, it was also revealed that as more functional groups were attached on the benzene ring, the decomposition of the VOCs was much easier than less ones. As for aliphatic VOCs, it was concluded that the longer carbon chain was, the higher the removal efficiency was.

Besides, main by-products generated from VOC decomposition using EB were all listed with respect to VOCs concerned. Since by-products obtained from EB irradiation bring about a secondary problem, EB hybrid techniques have been reviewed to find out a way to work it out. In the end, an EB-catalyst hybrid was evaluated as an alternative technique to remove VOCs more effectively than EB-only system since much less by-products were generated. This hybrid included support materials such as cordierite, Y-zeolite, and $\gamma$-alumina.

\section{ACKNOWLEDGEMENTS}

This work was supported by the Korean Ministry of Environment as part of "The Eco-Technopia 21 Project" and the Konkuk University. In addition, this was supported by the Korea Ministry of Education as "The Second Stage of BK21 Project" and the Seoul Environmental Science \& Technology Center (SEST), KOREA.

\section{REFERENCES}

Atkinson, R. (1985) Kinetics and mechanism of the gasphase reactions of the hydroxyl radical with organic compounds under atmospheric conditions. Chemical Reviews 85, 172-181.

Boulamanti, A.K., Korologos, C.A., Philippopoulos, C.J. (2008) The rate of photocatalytic oxidation of aromatic volatile organic compounds in the gas-phase. Atmospheric Environment 42, 7844-7850.

Chaichanawong, J., Tanthapanichakoon, W., Charinpanitkul, T., Eiad-ua, A., Sano, N., Tamon, H. (2005) Hightemperature simultaneous removal of acetaldehyde and ammonia gases using corona discharge. Science and Technology of Advanced Materials 6, 319-324.

Chmielewski, A.G. (2007) Industrial applications of electron beam flue gas treatment-from laboratory to the practice. Radiation Physics and Chemistry 76, 14801484.

Chmielewski, A.G., Haji-Saeid, M. (2004) Radiation technologies: past, present and future. Radiation Physics and Chemistry 71, 16-20.

Chmielewski, A.G., Ostapczuk, A., Zimek, Z., Licki, J., Kubica, K. (2002) Reduction of VOCs in flue gas from coal combustion by electron beam treatment. Radiation Physics and Chemistry 63(3-6), 653-655.
Chmielewski, A.G., Sun, Y., Bulka, S., Zimek, Z. (2007) Review on gaseous chlorinated organic pollutants electron beam treatment. Radiation Physics and Chemistry 76(11-12), 1795-1801.

Doi, Y., Nakanishi, I., Konno, Y. (2000) Operational experience of a commercial scale plant of electron beam purification of flue gas. Radiation Physics and Chemistry 57(3-6), 495-499.

Faisal, I.K., Aloke, K.G. (2000) Removal of volatile organic compounds from polluted air. Journal of Loss Prevention in the Process Industries 13, 527-545.

Frank, N.W. (1995) Introduction and historical review of electron beam processing for environmental pollution control. Radiation Physics and Chemistry 45, 9891002.

Futamura, S., Einage, H., Kabashima, H., Hwan, L.Y. (2004) Synergistic effect of silent discharge plasma and catalysts on benzene decomposition. Catalysis Today 89(1-2), 89-95.

Futamura, S., Gurusamy, A. (2005) Synergy of nonthermal plasma and catalysts in the decomposition of fluorinated hydrocarbons. Journal of Electrostatics 63(6-10), 949-954.

Hakoda, T., Yang, M., Hirota, K., Hashimoto, S. (1998) Decomposition of volatile organic in air by electron beam and gamma ray irradiation. Journal of Advanced Oxidation Technologies 3(1), 79-86.

Han, D.H., Stuchinskaya, T., Won, Y.S., Park, W.S., Lim, J.K. (2003) Oxidative decomposition of aromatic hydrocarbons by electron beam irradiation. Radiation Physics and Chemistry 67, 51-60.

Hashimoto, S., Hakoda, T., Hirata, K., Arai, H. (2000) Low energy electron beam treatment of VOCs. Radiation Physics and Chemistry 57, 485-488.

Hirota, K., Hakoda, T., Arai, H., Hashimoto, S. (2002) Electron-beam decomposition of vaporized VOCs in air. Radiation Physics and Chemistry 65(4-5), 415-421.

Hirota, K., Hakoda, T., Taguchi, M., Takigami, M., Kim, H., Kojima, T. (2003) Application of electron beam for the reduction of PCDD/F emission from municipal solid waste incinerators. Environmental Science and Technology 37(14), 3164-3170.

Hirota, K., Matzing, H., Paur, H.R., Woletz, K. (1995a) Analyses of products formed by electron beam treatment of VOC/air mixtures. Radiation Physics and Chemistry 45(4), 649-655.

Hirota, K., Woletz, K., Paur, H.R., Mtzing, H. (1995b) Removal of butylacetate and xylene from air by electron beam a product study. Radiation Physics and Chemistry 46(4-6), 1093-1097.

Jeon, E.C., Kim, K.J., Kim, K.H., Chung, S.G., Sunwoo, Y., Park, Y.K. (2008) Novel hybrid technology for VOC control using an electron beam and catalyst. Research on Chemical Intermediates 34(8-9), 863-870.

Khan, F.I., Ghoshal, A.K. (2000) Removal of volatile organic compounds from polluted air. Journal of Loss Prevention in the Process Industries 13, 527-545.

Kim, J.C. (2002) Factors affecting aromatic VOC removal 
by electron beam treatment. Radiation Physics and Chemistry 65, 429-435.

Kim, J.C., Getoff, N., Jin, J. (2006a) Catalytic conversion of $\mathrm{CO}_{2}-\mathrm{CH}_{4}$ mixture into synthetic gas- Effect of electron-beam radiation. Radiation Physics and Chemistry 75, 243-246.

Kim, J.C., Son, Y.S., Kim, K.J., Lim, Y.J., Chung, S.G., Sonwoo, Y. (2010) Combined radiolytic and catalytic oxidizing method to remove toluene in gas phase. Radiation Physics and Chemistry 79, 797-802.

Kim, J., Han, B., Kim, Y., Lee, J.H., Park, C.R., Kim, J.C., Kim, J.C., Kim, K.J. (2004) Removal of VOCs by hybrid electron beam reactor with catalyst bed. Radiation Physics and Chemistry 71, 427-430.

Kim, K.J., Kim, J.C., Sunwoo, Y. (2005) Development of hybrid technology using E-beam and catalyst for aromatic VOCs control. Radiation Physics and Chemistry 73(2), 85-90.

Kim, K.J., Park, K.N., Kim, J.C., Sunwoo, Y., Son, Y.S., Kim, K.H. (2006b) A study of Hexane decomposition using electron beam irradiation under background gases. Journal of Korea Society for Atmospheric Environment 22(5), 724-730.

Kohno, H., Berezin, A., Chang, J., Yamamoto, T., Shibuya, A., Honda, S. (1998) Destruction of volatile organic compounds used in a semiconductor industry by a capillary tube discharge reactor. IEEE Transactions on Industry Applications 34(5), 953-966.

Licki, J., Chmielewski, A.G., Iller, E., Zimek, Z., Mazurek, J., Sobolewski, L. (2003) Electron-beam flue-gas treatment for multicomponent air-pollution control. Applied Energy 75(3-4), 145-154.

Lu, B., Zhang, X., Yu, X., Feng, T., Yao, S. (2006) Catalytic oxidation of benzene using DBD corona discharges. Journal of Hazardous Materials 137(1), 633-637.

Machi, S. (1983) Radiation technology for environmental conservation. Radiation Physics and Chemistry 22(12), 91-97.

Machi, S. (2004) Role of radiation processing for sustainable development. In Emerging Applications of Radiation Processing, IAEA-TECDOC-1386, Vienna, pp. 513.

Magureanu, M., Mandache, N.B., Eloy, P., Gaigneaux, E.M., Parvulescu, V.I. (2005) Plasma-assisted catalysis for volatile organic compounds abatement. Applied Catalysis B: Environmental 61(1-2), 12-20.

Mätzing, H., Hirota, K., Woletz, K., Paur, H.R. (1994) Product study of the electron beam induced degradation of volatile organic compounds (VOC). Journal of Aerosol Science 25(1), S325-S326.

Moon, S.L. (2003) A study on plasma/catalytic synergy effect for VOCs removal. Korean Journal of Ksee 25(7), 810-815.

Ogata, A., Yamanouchi, K., Mizuno, K., Kushiyama, S., Yamamoto, T. (1999) Decomposition of benzene using alumina-hybrid and catalyst-hybrid plasma reactors. IEEE Transactions on Industry Applications 35(6), 1289-1295.
Ostapczuk, A., Chmielewski, A.G., Honkonen, V., Ruuskanen, J., Tarhanen, J., Svarfvar, B. (1999) Preliminary test in decomposition of styrene by electron beam treatment. Radiation Physics and Chemistry 56(3), 369-371.

Päur, H.-R., Baumann, W., Mätzing, H., Jay, K. (1998) Electron beam induced decomposition of chlorinated aromatic compounds in waste incinerator offgas. Radiation Physics and Chemistry 52(1-6), 355-359.

Päur, H.R., Mätzing, H. (1993) Electron beam induced purification of dilute off gases from industrial processes and automobile tunnels. Radiation Physics and Chemistry 42(4-6), 719-722.

Päur, H.-R., Mätzing, H., Woletz, K. (1991) Removal of volatile organic compounds from industrial off gas by irradiation induced aerosol formation. Journal of Aerosol Science 22(1), S509-S512.

Penetrante, B.M., Hsiao, M.C., Bardsley, J.N., Merritt, B.T., Vogtlin, G.E., Wallman, P.H., Kuthi, A., Burkhart, C.P., Bayless, J.R. (1995) Electron beam and pulsed corona processing of carbon tetrachloride in atmospheric pressure gas streams. Physics Letters A 209(1-2), 6977.

Penetrante, B.M., Hsiao, M.C., Bardsley, J.N., Merritt, B.T., Vogtlin, G.E., Kuthi, A., Burkhart, C.P., Bayless, J.R. (1997) Decomposition of methylene chloride by electron beam and pulsed corona processing. Physics Letters A 235(1), 76-82.

Penetrante, B.M., Hsiao, M.C., Bardsley, J.N., Merritt, B.T., Vogtlin, A., Kuthi, G.E., Burkhart, C.P., Bayless, J.R. (1998) Primary decomposition mechanism in electronbeam and electrical discharge procession of volatile organic compounds: Environmental Applications of Ionizing Radiation. Willey, New York, pp. 205-323.

Person, J.C., Ham, D.O. (1988) Removal of $\mathrm{SO}_{2}$ and $\mathrm{NO}_{\mathrm{x}}$ from stack gases by electron beam irradiation. Radiation Physics and Chemistry 31, 1-8.

Rafson, H.J. (1998) Odor and VOC control handbook, McGraw-Hill.

Shepson, P.B., Sedney, E.O., Corse, E.W. (1984) Ring fragmentation reactions on the photooxidations of toluene and o-xylene. Journal of Physical Chemistry 88, $4122-4126$.

Sun, Y., Chmielewski, A.G., Bulka, S., Zimek, Z. (2006) Influence of base gas mixture on decomposition of 1,4dichlorobenzene in an electron beam generated plasma reactor. Plasma Chemistry and Plasma Processing 26, 347-359.

Sun, Y., Chmielewski, A.G., Bulka, S., Zimek, Z. (2008) Organic pollutants treatment in gas phase by using electron beam generated non-thermal plasma reactor. Chemicke Listy 102, s1524-s1528.

Sun, Y., Chemielewski, A.G., Bulka, S., Zimek, Z. (2009) Decomposition of toluene in air mixtures under electron beam irradiation. Nukleonika 54(2), 65-70.

Tanthapanichakoon, W., Charinpanitkul, T., Chaiyo, S., Dhattavorn, N., Chaichanawong, J., Sano, N., Tamon, H. (2004) Effect of oxygen and water vapor on the removal of styrene and ammonia from nitrogen by non- 
pulse corona-discharge at elevated temperatures. Chemical Engineering Journal 97, 213-223.

Vazquez, P.G., Lopez, V.H., Carrasco, A.H., Mijangos, R.R., Garcia, G.R. (2002) Calculation of absorbed dose of low-energy electron beam by an approximate method. Radiation Physics and Chemistry 64(3), 181-187.

Won, Y.-S., Han, D.-H., Stuchinskaya, T., Park, W.-S., Lee, H.-S. (2002) Electron beam treatment of chloroeth- ylenes/air mixture in a flow reactor. Radiation Physics and Chemistry 63(2), 165-175.

Wu, C., Hakoda, T., Hirota, K., Hashimoto, S. (1997) Effect of ionizing radiation on decomposition of xylene and benzene contanined in air. Journal Aerosol Research Japan 12(2), 115-123.

(Received 24 March 2010, accepted 14 June 2010) 